\title{
In Vitro Evaluation of the Antagonistic Effect of Some Native Trichoderma Strains Against Economically Important Foliar Pathogens of Rubber
}

\author{
P.K.N.N. Sandamali ${ }^{1}$, T.H.P.S. Fernando ${ }^{2 *}$, G. Chandrasena ${ }^{1}$, D. Siriwardane ${ }^{2}$ \\ ${ }^{1}$ Department of Export Agriculture, Uva Wellassa University, Sri Lanka \\ ${ }^{2}$ Department of Plant Pathology and Microbiology, Rubber Research Institute, Dartonfield, \\ Agalawatta, Sri Lanka \\ *thpsfernando@yahoo.com
}

\begin{abstract}
Rubber plants are subjected to serious fungal diseases and among them, the losses caused by foliar diseases play an important role. The frequent use of chemical fungicides to control causative pathogens leads to environmental pollution, hazardous to human and may lead to the development of new chemical resist pathogenic strains. Trichoderma species are ubiquitous soil-borne Ascomycetes noted for their biocontrol capabilities against many economically important plant pathogens. Hence, an attempt was made to investigate the antagonistic effect of some native Trichoderma isolates on the plant pathogenic fungi; Colletotrichum sp., Corynespora cassiicola, Phytophthora sp. and Drechslera heveae. Foliar pathogens were isolated from Rubber Research Institute, Dartonfield, Agalawaththa and identified based on the symptoms, cultural and reproductive characteristics. Five Trichoderma isolates isolated from different habitats in Sri Lanka were tested in vitro for their antagonistic effects against the four foliar pathogens. The results obtained from dual culture tests showed that all the five Trichoderma isolates effectively checked the growth of the four foliar pathogens. The test antagonists grew faster than the pathogen limiting their growth. Trichoderma isolate A was the best antagonist against Drechslera heveae, Corynespora cassiicola and Colletotrichum sp. showing inhibition of $75.63 \%, 51.34 \%$ and $74.46 \%$ respectively. Isolate B showed the best inhibition (70.99\%) against Phytophthora sp. All antagonists showed their lowest inhibition against $D$. heveae. In conclusion, all the tested Trichoderma isolates showed antagonistic effect on the four foliar pathogens under investigation. Therefore, the fungal isolates under investigation can be used for further greenhouse and field studies to confirm the feasibility of using for the management of rubber foliar pathogens.
\end{abstract}

Keywords: Trichoderma spp., Drechslera heveae, Corynespora cassiicola, Colletotrichum spp., Phytopthora spp, Bio-control agents 